\title{
Application of GIS on Research of Horizontal Refraction in Polygonometry on Network
}

\author{
Abdusali Suyunov ${ }^{1, *}$, Shukhrat Suyunov ${ }^{1}$ and Olim Urokov ${ }^{1}$ \\ ${ }^{1}$ SamSACEI, Department of Geodesy and Cartography, 140147, Samarkand, Uzbekistan
}

\begin{abstract}
The article examines the influence of refraction on the results of measuring the horizontal angle in special places. In the conditions of the hot and arid climate of Uzbekistan in the polygonometric network of river banks, according to the results of field experiments, the new version of the developed methodology of the GIS makes it possible to increase the accuracy of measuring horizontal angles and lengths of lines. Significant temperature changes along the water and the coast, on rocks, in the upper layers of sand-concrete pavements are also explained by the properties of the heat and radiation balance.

Keywords. Electronic technologies, high-precision geodetic measurements, the influence of refraction, atmospheric measurement, uneven distribution of the light beam, modern devices, positive opportunities.
\end{abstract}

\section{Introduction}

One of the most important reasons limiting the accuracy of measuring horizontal angles using modern technology of high-precision angular measurements is not instrumental errors, but an error called horizontal refraction of the atmospheric atmosphere caused by external environmental influences.

Studying this phenomenon and eliminating its harmful effects, triangulation and polygonometry is the first task in science and industry to improve the accuracy of networks.

This problem is taken into account when conducting geodetic measurements in developed countries, including Russia, Ukraine, Germany, the United States and other countries, to improve the accuracy of measurements, taking into account the horizontal refractive properties, which significantly affect the measurement results.

In large-scale cartographic work, geodesy makes all the requirements related to the accuracy of the geodetic base, especially angular measurements, forcing to revise the newly created and developed systems for constructing the geodetic base, and requires the development of a new method.

In this regard, one of the important tasks is to ensure that the external environment is not always in a stable state, but to change it from time to time in established ways.

The new basic geodetic survey system shortens the sides of triangles and polygon measurements as it requires more compaction of points. As a result, we observe a slight

*Corresponding author: suyunov303@inbox.ru 
deterioration in the state of light transmission along the uneven line. In such cases, it is necessary to improve the accuracy of the angular measurement results. To overcome such problems, it is necessary to study new cases of the influence of horizontal refraction on the accuracy of the results of measuring horizontal angles in urban polygonometry, i.e. laws of subordination of the atmosphere to height..

To accomplish these tasks, it is important to determine and improve a modern solution for measuring the impact of the external environment on horizontal angle measurements.

In the Strategy for the Further Development of the Republic of Uzbekistan for 20172021, the Republic of Uzbekistan "On Geodesy and Cartography", Decree of the President of the Republic of Uzbekistan dated May 31, 2017, No. UP-5065 "On Further Improving the Activities of the State Committee for Land Resources, Geodesy, Cartography and cadastre of the Republic of Uzbekistan" other regulatory documents [1].

With the development of this area, the scientific problems of urban polygonometry using horizontal angle and linear distance measurements are expanding, which requires taking into account the effect on horizontal angle measurements in hot, very hot and dry climates.

It is important and urgent to find a solution to these problems, especially in the context of the climate of the Karshi city of the Republic of Uzbekistan, in dry and hot climates, the variability of the atmosphere is very high, which leads to significant errors in the measurement of the horizontal angle.

Methods for taking into account the influence of the atmosphere on measurements of the horizontal angle have been tested to one degree or another in the middle latitudes of the normative climate and in other relatively lower regions of the republic's climate, but in an arid climate, they have not been studied at all.

The influence of horizontal refraction on the results of geodetic measurements was studied in scientific research of scientists of the republic A.S.Suyunov and T.M.Abdullaev, and they have achieved certain positive results [3,4,6,9].

However, the work of the aforementioned scientists and researchers did not study the implementation and improvement of the accuracy required to measure these objects in modern new geodetic instruments, as well as its regional organization.

Much attention in the country is paid to the construction of new buildings and structures on the basis of comprehensive geodetic control with high precision, accuracy and standards. However, no method has been developed to improve accuracy by determining the degree of influence of the near-earth layer of the atmosphere on the results of geodetic measurements. Thus, this article to some extent meets the above goals and objectives.

Sokoba's research on reforestation and riverbank research is based on a very short (sixhour) experience with a number of drawbacks $[5,7,8,11]$.

Therefore, the effect of refraction on geodetic measurements has not yet been studied in urban polygonometry.

In fact, the solution to this question is not enough for Marchenko [5] investigated in his polygonometric system of wall mounting, specifying the refraction effect in this case, without saying a word about the effect of light refraction. At the same time, polygon paths along city streets and river banks are approaching additional established signs, which leads to the fact that horizontal angles are distorted and significantly increase.

In particular, ehe lateral refraction effect is especially noticeable in the lower classes of polygonometry when it comes to the accuracy of measuring horizontal angles. [6]. The reason is as follows:

(a) Polygonometry usually develops in a plane, in a closed space, that is, according to the temperature (density) of the air, as well as the refraction of the light beam under conditions of a strong influence of the air temperature below and the height of the air atmosphere up to $1.5 \mathrm{~m}$ and in places with obstacles. Especially in polygonometry of fields 
3 and 4 and urban polygonometry, the influence of a light beam on the state "not between obstacles, but between obstacles" should be noted separately. Triangulation is typically used primarily in open, intersecting, or semi-enclosed areas, that is, in conditions where it is visible at all distances or partially so that light passes through the lower surface of the earth.

b) In polygonometry, the azimuth transfer error is approximately 1.3 times greater than the triangulation error [2,10,12-16].

c) In the lower classes of polygonometry, when the line length is $0.5-1 \mathrm{~km}$, small, welldefined refractive fields have a strong refractive effect on the measured geodetic results of all polygonometric trajectories. Thus, the values of the effect of the refractive field in the lower classes of the polygonometric trajectory will be very close to the indices of the refractive field in polygonometry of the 1 st and 2 nd classes.

The microclimatic regime in the surface layer of the atmosphere is characterized, first of all, by superadiabetic vertical temperature gradients during the day and nighttime inversion of the temperature distribution and their significant differences in the horizontal plane and even greater gradients in the near-surface layers.

As is known from the courses of meteorology, the physical basis of these properties stems from the heat and radiation balance in the near-surface layer of the atmosphere.

The influence of the local climate of water bodies and rivers and the microclimate of coastal areas is known.

Consequently, it reduces the daily and annual amplitudes of air temperature near water bodies; in summer, the temperature decreases along the coast and above the water surface during the day, and at night it is higher than in places far from water bodies; water bodies heat up during the winter months, and the adjacent drylands are relatively cooled; The range of influence of shores stretching for tens, and sometimes hundreds of kilometers, depends mainly on the size of the reservoirs.

Throughout the water and along the coast, on the rocks, in the upper layers of sandconcrete pavements, there are obvious temperature drops;

Again, this is due to the properties of heat and radiation balance.

Based on the results of Suyunov's and Abdullaev's installation of meteorological stations in the upper water layer in the region of 5 geodetic points $(5-10 \mathrm{~m})$ around the Koratepa reservoir, the effect of lateral refraction was determined. did not take into account the influence of the external environment in field experimental studies.

\section{Methods}

\subsection{Study area}

In the experimental region, the refractive index $n$ of the air atmosphere has a predominant effect on the horizontal temperature gradient. In coastal soil conditions, horizontal moisture and temperature gradients can have a significant impact on coastal areas. From a geodetic point of view, we found answers to the following questions to study and account for the effect of lateral refraction to improve the accuracy of horizontal angle measurements:

a) values of horizontal gradients of temperature and humidity of air at a distance of the first ten meters from the surface of the earth and water of the atmosphere near the earth;

b) in each direction, in different weather conditions, horizontal gradients of temperature and humidity during the day, the path of change in hours;

c) density of the range of spatial distribution of the light beam above the surface layer of the atmosphere, etc. 
The answers to these questions were found during a survey conducted by the authors in June 2018 and July-August 2019 at the geodetic polygon in the Khudoizod massive which is located in Karshi city of the Republic of Uzbekistan.

\subsection{Methods}

Points for meteorological observations were selected from open areas on the left bank of the Beshkent River. The glasses were set 12 meters from running water. This river flows out of the Beshkent Canal, not far from the Khudoizod massive $(0.8-1.0 \mathrm{~km})$. This place is distinguished by its unusual width, landscape, and natural features. Observation platforms of low (2-4 m) relief, complex, are located at a depth of several tens of meters wide and in hills. The width of the massif directly with the observation deck is 3.5 meters towards the lower reaches of the river, the width of the coastline is 30-35 meters, the height of the coastline is 3-3.5 meters. The azimuth of the river flow is $125^{\circ}$. It is asymmetrical on the left bank of the Beshkent River, stretches $1-1.5 \mathrm{~km}$ to the north and north-west, and is located at the foot of the hills, then turns into a gentle hill, therefore it is located at a distance of 700-900 m from Beshkent. the absolute height of the points is close to the right bank of the river valley and depends on the river bed. In 2018, at the main observation site, the temperature was measured from the earth's surface, at a height of $0.75 \mathrm{~m}$, and temperature and humidity - at a height of $1.5 \mathrm{~m}$. Atmospheric pressure, wind speed, and direction were also determined. The state of heaven was recorded. At the same time, air temperature and humidity were observed on the water surface at the above-mentioned heights and its readings were recorded. For this, a special boat was built and a mast was attached to it. Modern electronic psychrometers were installed on the masts. All measurements were made by the members of the expedition.

Thus, at the aforementioned heights, meteorological data were measured at the same height above land and water at a distance of $3.5 \mathrm{~m}$ from the coast, from the water. Aneroid, hand-held anemometer, psychometers were used to measure meteorological elements. Before all measurements, the measuring instruments were inspected.

At the same time, it was taken into account that the height of the aiming beam when viewing the place itself is legally greater than at ground level.

For the measurement of meteorological elements: psychrometers-thermometers with fabric protection (coefficient of continuity 200 seconds) and scale values of $0.1^{\circ}$ and $0.2^{\circ}$ C. Particular attention was paid to the measurement of air temperature. All thermometers were checked and compared every hour. Their readings were brought to the readings of a psychrometer installed at a height of 1.5 meters in the main zone. This method significantly improves the detection of gradients with psychrometers and emphasizes their accuracy. The reason is that, without correction by using thermometers, artificial ventilation becomes absolutely necessary. Finally, due to the variability of solar radiation, there will also be significant (up to $1^{\circ} \mathrm{S}$ ) daily variability, which depends on the strength and direction of the wind speed.

In each measurement, thermometers were counted three times, and the second and third counts were made at intervals of 2-4 min, respectively. The result is the arithmetic mean of these numbers. We did not measure temperature, although the science of meteorology recommended observing air temperature readings at microclimate altitudes $(20 \mathrm{~cm}$ and 50 $\mathrm{cm}$ ).

It should also be noted that each psychrometer has its own radiation errors, and in meteorology, it is generally preferable to measure gradient values with a single psychrometer, regardless of the fact that these measurements are not simultaneous.

We, on the other hand, used two psychrometers and counted them simultaneously, which reduced radiation errors by comparing thermometers to each other every hour. 
Compared to the meteorological measurements of our 2019 field experiments, the observations made in 2018 were closely related to simultaneous angle measurements. In these measurements, the main observation point is located at a distance of $7 \mathrm{~m}$ from the edge of the water boundary.

In addition, the horizontal gradient of air humidity in 2018 has not been determined. In 2019, air temperature, humidity, and wind speed were determined.

Accordingly, all measurements were made on two additional psychrometers. Psychrometers are located on the left bank of the embankment at a distance of 15 meters from the water and 50 meters from the station, as well as at the station on the right bank. In turn, in 2018, additional air temperatures were measured in the direction transverse to the river at a distance of $400 \mathrm{~m}$ from the station. During the observation, the openness of the sky was recorded on a five-point scale.

All observations were usually carried out from morning to evening, and sometimes during the day (24 hours). To facilitate further processing and understanding, the main point of meteorological observations has been moved to the origin of the spatial coordinate system.

The system plane coincides with the horizon plane. The main arrow is directed perpendicular to the stream of the river. As a result, the main axis runs in the direction of the riverbank, and in fact, it is a parallel line equal to the temperature and humidity of the air [17].

Thus,

$$
\frac{d T}{d Y}, \frac{d T}{d Z}, \frac{d \mathrm{e}}{d Y} \text { and } \frac{d e}{d Z}
$$

(1) Differences in temperature and humidity are proportional to horizontal and vertical gradients.

\section{Results}

We can arbitrarily call gradients positive or negative if the temperature and humidity of this coordinate axis fall or fall in their direction. The average values of the horizontal temperature ( $\mathrm{t}$ ) and air humidity of interest to us are calculated using the results of measurements in the middle of the river and river coordinates $(x=0, u=50 \mathrm{~m}, \mathrm{z}=0)$.

Fig. 1 The results of field observations in 2018 are presented in the middle of the river, at a distance of $5 \mathrm{~m}$ above the water level on land and at a height of $1.5 \mathrm{~m}$ along the river bank at the water level, demonstrating a picture of daily changes in air temperature drops.

All of the above observations were carried out with a cloudy, opaque (variable), and open sky (sunny weather) wind at a speed of $0.5 \mathrm{~m} / \mathrm{s}$ in the direction of the river flow. During the day, the wind force in this direction increased significantly and reached $4-5 \mathrm{~m} / \mathrm{s}$ $[18,20]$.

The air temperature difference shown in the graphs is formed by the following formula:

$$
\Delta T=T_{\mathrm{\kappa}}-T_{\mathrm{c}}
$$

Where, $T_{K}$ is the air temperature on the river bank; $T_{C}$ - air temperature near the groundwater level. These values significantly decrease in the south of the Republic of Uzbekistan on sunny days, to very large $2^{\circ} 5 \mathrm{C}$ ), when the sky is variable cloudy cool days (up to $0^{\circ}, 3-0^{\circ}, 5 \mathrm{C}$ ). Differences in $\Delta \mathrm{T}$ are positive for negative values in the morning, evening, and night, between 7:30 am and 8:30 pm after sunrise and between 7:00 pm and 20:00 pm before sunset. (During the field experiment, sunrise was 6:30 am and sunset was 8:40 pm. (Fig. 1.) 
The uneven distribution of real moisture in the atmosphere is very interesting. During the day, at a height of $1.5 \mathrm{~m}$ on the river bank, at a distance of $15 \mathrm{~m}$ from the river bank, the humidity is relatively high, the wind blows weakly in all directions up to $5 \mathrm{~m}$ above the river surface. In the morning, evening and night, on the contrary, the water on the surface confirms that the humidity is quite stable and very high.
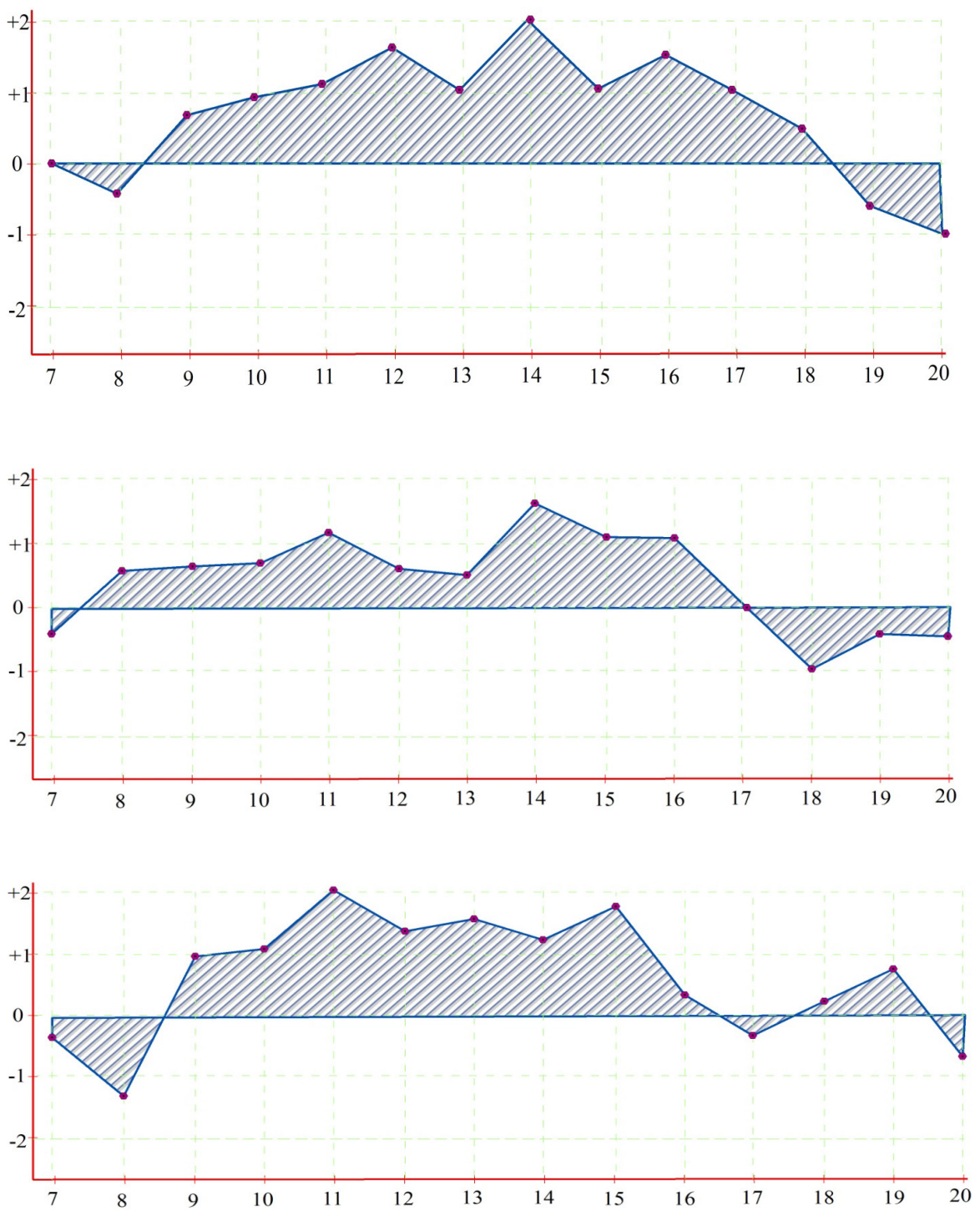

Fig. 1. The daytime observation results 

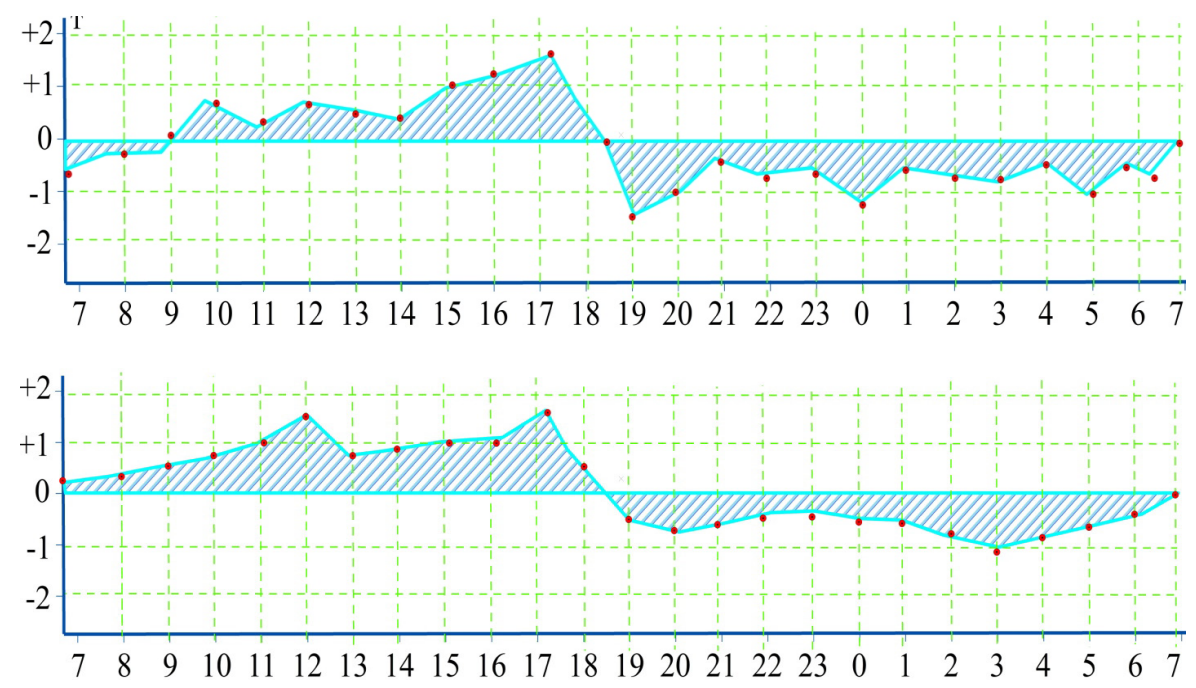

Fig.2. Results of daily monitoring

\section{Discussion and conclusion}

GIS is an existing multi-faceted environmental dataset based on electronic computing technologies $[10,19]$. GIS is designed to provide easy viewing of data available at different levels of human economic activity. The main stage in the development of GIS is the last 7-8 years. This is due to the fact that the computer-aided design of all work processes based on geographic data is organized technologically and ideologically.

GIS integrates information of different content and distribution into one system, creating a coherent system for analyzing geographic data. Regardless of how important it is to understand and manage the various activities and resources, if GIS are not linked, this issue remains unresolved.

We came to the following conclusions in the experiment:

- based on the measured meteorological data of the atmospheric atmosphere under the conditions under study, the possibility of studying the regularities of the distribution of the microclimate that creates a refractive field has been established:

- during the day, we showed that the influence of lateral refraction on the results of measuring the horizontal angle and line in hot and dry climates can be established in river conditions in the south of the country, every two hours of the day and in various climatic conditions:

- using the meteorological elements identified in the field, the geodetic measurements made in the river bank polygon as corrections were applied to the lateral refraction results and the results were improved:

These are new solutions used by GIS to combat external influences and improve the accuracy of polygon networks.

The authors are grateful to the staff of the Department of Geodesy and Mining of the Karshi Engineering-Economics Institute for their contribution to the collection of scientific results in this article. 


\section{References}

1. Decree of the president of the Republic of Uzbekistan, "About the strategy for further development of the Republic of Uzbekistan", PF-4947 dated February 7, 2017

2. A. S. Suyunov, Sh. A. Suyunov, On the accuracy of geodetic measurements in the conditions of the Republic of Uzbekistan (2017)

3. T. M. Abdullaev, The study of patterns of action and the search for methods of accounting for lateral refraction when measuring horizontal angles ( Tash STU, 2005).

4. Sh. A. Suyunov, U.E. Karimova, Sh.Sh. Fayziev, Special volume, J. Bull. Geograph. Society Uzbekiston (2018)

5. Sh. A. Suyunov, Doctoral research disser., (2018)

6. Sh. A. Suyunov, S. A. Tashpulatov, G. Mullajanova, Modern scientific challenges and trends. Warsaw, 12 ( 2) (2019)

7. A. S. Suyunov, Sh. I. Fayziyev, Intr. J. Adv. Res. Sci., Engin. Tech. 6 (11) (2019)

8. A. S. Suyunov, Sh. A. Suyunov, G.M. Mullajanova, Intr. J. Adv. Res. Sci., Engin. Tech.. 6 (11) (2019)

9. A. S. Suyunov, Sh. I. Fayziyev, Studying the experience of full breakage on the streets of karshi in kashkadarya region. Intr. J. Adv. Res. Sci., Engin. Tech. 6 (11) 1187311875 (2019)

10. A. S. Suyunov, Sh. A. Suyunov, G.M. Mullajanova, Analysis of the qualification developmentof natural hazards at geoecological monitiring of landslide hazardeus territiries. Intr. J. Adv. Res. Sci., Engin. Tech. 6 (11) 11534-11537 (2019)

11. A. S. Suyunov, A. A Salahiddinov, Sh. A. Suyunov, Analysis of the influence of the atmosphere surface layer on the measurement made by electronic total stations. Intr. J. Adv. Res. Sci., Engin. Tech. 4 (1) 3098-3101 (2017)

12. I. S. Trivoy, The nature of the temperature field in the city and the phenomenon of anamal lateral refraction. "Geoecological problems of urbanized territories" (Характер температурного поля городе и явление анамальной боковой рефракции. “Геоэкологические проблемы урбанизированных территорий”) 15-16 (1999)

13. A. S. Suyunov, Sh.A. Suyunov, Refraction accounting methods for geodetic measurements (Методы учета рефракции при геодезических измерениях) 158 (2020)

14. O. B. Vshivkova, Profile aggregation as a means of accounting for the influence of the surface layer of the atmosphere with minimal costs (Профильное колплексирование как средство учета влияния приземного слоя атмосферы с минимальными затратами) 4 3-11 (2017)

15. A. S. Suyunov, Sh. A. Suyunov, M. K. Isakov, Geodetic refraction in Central Asian. (Ўрта осиё шароитида геодезик рефракиия) conditions Materials of the XIV Republican scientific-practical conference. 2 36-39 (2017)

16. A. S. Suyunov, Sh. A. Suyunov, U. Berdikulov, A new way to take into account refraction in trigonometric leveling in Uzbekistan (Ўзбекистон шароитида тригонометрик нивелирлашда рефракцияни хуисобга олишнинг янгича йўли). J. Irr. And Mel. 2 55-57 (2018)

17. A. E. Fedorishchev, L. S. Xijak, Investigation of the temperature field in order to take into account refractive distortions in the boundary layer of the atmosphere. (Исследование температурного поля с иелью учета рефракционных искажений в пограничном слое атмосферы). J. Geo. Car. 21 66-69 (1995) 
18. M. Hennes, Zum Refraktionseinfluss auf terrestrische geodдtische Messungen im Kontext der Messtechnik und der Instrumentenentwicklung. Fldchenmanag. Und Bodenordn. 2 73-86 (2016)

19. W. Gurtner, G. Beutler, The use of meteorological data in large scale GPS networks. Spring Meet, Baltimore. 3 23-28 (1994)

20. P. Harzer, Berehningder Ablenrungender Lichtetrahlenin der Erdefufrein meterologiech - physikalische Grundlage. Publ. Der Sternwartein Kiel, 24 (1982) 